\title{
Mononeuropathy of the maxillary nerve branches associated with COVID-19
}

\author{
Mononeuropatia dos ramos do nervo maxilar associada à COVID-19 \\ Mononeuropatía de las ramas del nervio maxilar asociada con COVID-19 \\ Cristiano GAUJAC ${ }^{1}$ \\ Wilton Mitsunari TAKESHITA ${ }^{2}$ \\ Danielle Pereira GAUJAC ${ }^{3}$ \\ Irineu Gregnanin PEDRON ${ }^{4}$ \\ Elio Hitoshi SHINOHARA ${ }^{5}$ \\ ${ }^{1} D D S, P h D$, Postdoctoral student in the Postgraduate Program in Dentistry at the Federal University of Sergipe - Dentistry Department, \\ 49060-100 Aracaju-SE, Brazil \\ ${ }^{2} D D S$, PhD, Federal University of Sergipe, teacher in the graduate and Postgraduate Program in Dentistry (Dentistry Departament) \\ 49060-100 Aracaju-SE, Brazil \\ ${ }^{3}$ MSc, PhD, Instituto Gaujac de Reabilitação Oral e Maxilofacial - 49026-010 Aracaju-SE, Brazil \\ ${ }^{4} D D S, M S c$, Assistent Professor, Universidade Brasil \\ ${ }^{5} \mathrm{DDS}, \mathrm{PhD}$, Assistant surgeon, Department of Oral Surgery and Maxillofacial Surgery, Hospital Regional de Osasco \\ 06216-240 Osasco - SP, Brasil
}

\section{Abstract}

This clinical note describes a case report where the patient notices that one of the symptoms suffered during COVID-19 infection is a mononeuropathy of the branches of the maxillary nerve, reviewing in the literature the findings of the affinity of the coronavirus to nerve fibers.

Descriptors: SARS Virus; Coronavirus Infections; Maxillary Nerve.

\section{INTRODUCTION}

In December 2019, the world was surprised by a viral epidemic in the city of Wuhan (China) that until that moment was considered a flu outbreak. In late January 2020 the World Health Organization (WHO) declared the epidemic as a public health emergency of international interest. In February 2020, the new virus was named coronavirus type- 2 associated with severe acute respiratory syndrome (SARS) and the resulting disease COVID-19 (Corona VIrus Disease 2019) ${ }^{1,2}$.

Signs and symptoms, which until then would be daily, may be within a clinical picture that characterizes COVID-19, and may go unnoticed by the patient, such as headache ${ }^{3,4}$, sore throat, congestion or coryza, nausea or vomiting, diarrhea and others less common as loss of taste and/or smell ${ }^{5}$.

The manifestations in the nervous system have been shown in the literature, apparently the human brain seems relatively spared, in the acute phase of the disease, with signs and symptoms less cited by patients as: headache $(8 \%)$, confusion $(9 \%)$, dizziness $(17 \%)$, impaired consciousness $(8 \%)$, anosmia $(6 \%)$, hypogeusia $(6 \%)$, acute cerebrovascular diseases $(3 \%)$, ataxia $(1 \%)$, and neuralgia ${ }^{6-8}$. new studies have demonstrated that injuries to the central nervous system are severe making rare injuries such as acute disseminated encephalomyelitis more common .

Many viral diseases can trigger an autoimmune response affecting the central or peripheral nervous system ${ }^{10}$. From a biomolecular point of view, viruses can infect peripheral neurons, using the active transport mechanism of the cell to access the central nervous system ${ }^{11}$. The coronavirus type- 2 presents an affinity for the receptor Angiotensinconverting enzyme 2 (ACE-2) in the membranes of spinal cord neurons ${ }^{12}$. ACE-2 receptor is also expressed in the central nervous system predominantly in thalamic nuclei, cerebellum and lower olive nuclei ${ }^{13}$.

The objective of this work is to make a self-report of a mononeuropathy of the maxillary nerve branches, associated with covid-19, bringing some observations perceived during the manifestations of the infection, which may give clues about the performance of the virus in the nervous system.

\section{CLINICAL CASE}

Patient, male, 46 years old, without associated comorbidity, maxillofacial surgeon, who has been working with facial pain for 20 years, infected by covid-19, at the beginning of the pandemic in Brazil. In a clinical evaluation the patient presented teeth without caries, without periodontal disease, did not present occlusal traumas or temporomandibular joint problems as well as in the masticatory muscles. There was no history of sinusitis. The infection occurred in the performance of her profession, in an emergency surgery, in a hospital environment, of a patient who had received eight shots in the face and was suspected of being infected by coronavirus. During the postoperative period, the air from the tracheostome was thrown towards the patient's eyes (surgeon). After five days the first symptoms appeared. At night, even in a resting position, there was a paroxysmal tenderness in the right hip with characteristics of stinging and tingling pain, which made it impossible for the patient to walk correctly, accompanied by intense shivering and trembling, with good response to dipyrone. The pain was slowly reduced until it disappeared completely in 24 hours. The second day was marked by extreme indisposition throughout the day. On the third 
day of symptoms, dizziness and dyspnea appeared, with extreme tiredness at the slightest physical effort, which persisted for more than four days. On the seventh day of symptoms the patient sought an emergency service, which was performed laboratory tests, chest radiography and the RT-PCR (reverse-transcriptase polymerase chain reaction), which confirmed the infection by COVID-19, without pulmonary involvement. On the eighth day there was discomfort in the eyeball on the left side throughout the day and when positioned in decubitus a paroxysmal pain appeared in the region of the canine, premolar and molar teeth on the same side, with characteristics of a continuous pain, well located, stinging and tingling. On sensitive examination, a positive symptom of dysesthesia associated with an allodynia was noticed, stimulated by a light manual pressure on the skin of the infra orbital nerve, with good response to dipyrone too. In addition to the above, the patient presented tachycardia (average of $130 \mathrm{bpm}$ at rest with some peaks of $200 \mathrm{bpm}$ ) and diarrhea (for more than 6 days) and the saturation, by oximetry, was around $93 \%$. There were no episodes of sore throat, headache, coryza, cough and fever.

DISCUSSION

The pathophysiology of neuropathic pain is complex and in viral cases may be associated with activation of the immune system and glia cells with release of proinflammatory cytokines, chemokines and other neuroexcitatory substances. The injury to peripheral nerves induces rapid and intense discharges for more or less prolonged periods in the absence of stimuli. Neuropathic pain is characterized by the appearance of hyperalgia, spontaneous pain, paresthesia and mechanical allodynia ${ }^{14}$. The cases of peripheral neuralgias by COVID-19 are rare, there is still no report of associated mononeuropathy in the literature, mainly with the involvement of cranial pairs.

Acute and subacute neuropathies are related to infectious or immune-mediated diseases. In this case there was a rapid resolution of the pain with the ingestion of dipyrone, which can characterize an acute neuropathy. The pains cited by patients are reported superficially. Muscular pain is one of the most common manifestations, 35 to $50 \%$ of the patients $s^{7,15,16}$, but in fact these muscular pains can be neuropathic pains, confused by the patients due to lack of knowledge and without due importance by health professionals due to other priorities of care that this disease requires.

An acute inflammatory picture of peripheral demyelinating neuropathy can be consequences of infection ${ }^{10}$. Shors ${ }^{16}$ found, in a patient with herpes zoster, that COVID-19 contributed to an exaggerated inflammatory response in the dorsal root ganglion, with severe neuralgia, even her initiating antiviral therapy within $12 \mathrm{~h}$ of initial presentation of herpes ${ }^{17}$. It is known that viruses can cause neuropathies but this particular virus, besides its new and little known behavior, seems to have a potential to induce neuropathies more frequently, due to its affinity for ACE-2 receptor, including the ability to cause a rare mononeuropathy in a cranial pair.

Pain and dysesthesia are the most common symptoms in idiopathic and acquired fine fiber neuropathy ${ }^{18}$. In this case there were two episodes of paroxysmal pain suffered by the patient, the first in the acute phase of the disease, in the hip region and the second in the chronic phase, affecting the branches of the maxillary nerve. It seems that most of the lesions affecting the central nervous system of the cranial portion are associated with the chronic phase of the disease ${ }^{8}$, contrary to the changes in the acute phase that may be associated with invasion of the central nervous system of the spinal portion, the possibility of acute myelitis secondary to viral invasion was considered by Zhao et al. ${ }^{11}$ who discuss the expression of ACE-2 receptor in the membranes of spinal cord neurons. The unbearable muscle pains cited since the onset of the epidemic may be largely neuropathic ${ }^{2}$. Despite the limitations found at the time of the pain felt, the sensitive tests performed by the patient brought a strong indication that the pain was a neuropathy.

The possible differential diagnoses for this pain would be sinusitis, but the patient had no history of sinusitis and the rapid evolution of pain with the also rapid resolution with the administration of dipyrone, in a single dose, without use of antibiotic, could rule out this possibility. Another differential diagnosis would be a trigger point, associated with problems in the masseter and temporal muscles, which was also discarded because it did not present any muscle or temporomandibular joint disorder. The patient also presented dentition in good health, with absence of caries, periodontal disease and absence of occlusal traumas.

The infection by COVID-19 and the involvement of the trigeminal nerve, in the case reported, may be associated with the route of inoculation of the virus (eyes) because it is known that the path of the infraorbital nerve is in the floor of the orbit and often in contact with the orbital content in its lower portion. As well as in cases of changes in taste and olfactory 
functions ${ }^{19}$ may be directly linked to the route of nasal contamination and rapid infection of the central nervous system through the olfactory bulbs ${ }^{20}$.

\section{REFERENCES}

1. World Health Organization. Coronavirus disease (COVID-19) pandemic. Geneva: WHO [consultation 09/01/2020]. Disponible in https://www.who.int/emergencies/diseases/nov el-coronavirus -2019

2. Zhu N, Zhang D, Wang W, Li X, Yang B, Song $\mathrm{J}$, et al. A novel coronavirus from patients with pneumonia in China, 2019. N Engl J Med. 2020; 382:727-33.

3. Belvis R. Headaches During COVID-19: My Clinical Case and Review of the Literature. Headache. 2020;60(7):1422-26.

4. Santos-Lasaosa S, Porta-Etessam J. Infiltración con onabotulinumtoxina y bloqueos en el paciente con cefalea y neuralgia: recomendaciones de seguridad frente a la infección por SARS-CoV-2. Neurologia. 2020;35(5):291-94.

5. Centers for Disease Control and Prevention (CDC) Guidance for Dental Settings - Interim Infection Prevention and Control Guidance for Dental Settings During the COVID-19 Response. $2020 \quad$ URL https://www.cdc.gov/coronavirus/2019ncov/hcp/dental-settings.html [accessed on 1 July 2020].

6. Chen N, Zhou M, Dong X, Qu J, Gong F, Han Y et al. Epidemiological and clinical characteristics of 99 cases of 2019 novel coronavirus pneumonia in Wuhan, China: a descriptive study. Lancet. 2020; 395:507-13.

7. Huang C, Wang Y, Li X, Ren L, Zhao J, Hu Y et al. Clinical features of patients infected with 2019 novel coronavirus in Wuhan, China. Lancet 2020; 395(10223):497-506.

8. Mao L, Jin H, Wang M, Hu Y, Chen S, He Q et al. Neurologic Manifestations of Hospitalized Patients With Coronavirus Disease 2019 in Wuhan, China. JAMA Neurol. 2020;77(6): 683-90.

9. Paterson RW, Brown RL, Benjamin L, Nortley $\mathrm{R}$, Wiethoff $\mathrm{S}$, Bharucha $T$ et al. The emerging spectrum of COVID-19 neurology: clinical, radiological and laboratory findings. Brain. 2020;143(10):3104-20.

10. Berger JR. COVID-19 and the nervous system. J Neurovirol. 2020;26(2):143-48.

11. Koyuncu OO, Hogue IB, Enquist LW. Virus infections in the nervous system. Cell Host Microbe. 2013;13(4):379-93.

12. Zhao K, Huang J, Dai D, Feng Y, Liu L, Nie S. Acute myelitis after SARS-CoV-2 infection: a case report., m. preprint, Editor. medRxiv 2020. Doi: 10.1101/2020.03.16.20035105
13. Allen AM, O`Callaghan EL, Mendelsohn FAO, Chai SY. Neuronal angiotensin. In: Squire LR (ed) Encyclopedia of Neuroscience. New York, Academic Press, 2009

14. Schaible HG. Pathophysiology of pain. Orthopade. 2006;36(1):8-16.

15. Li LQ, Huang T, Wang Y, Wang Z, Liang Y, Huang $T$, et al. COVID-19 patients' clinical characteristics, discharge rate, and fatality rate of meta-analysis. J Med Virol 2020;92(6): $577-83$

16. Xu XW, Wu XX, Jiang XG, Xu KJ, Ying LJ, Ma $\mathrm{CL}$, et al. Clinical findings in a group of patients infected with the 2019 novel coronavirus (SARS-Cov-2) outside of Wuhan, China: retrospective case series. BMJ. 2020;368:m792.

17. Shors AR. Herpes zoster and severe acute herpetic neuralgia as a complication of COVID19 infection. JAAD Case Rep. 2020;6:656-57.

18. Lacomis D. Small-fiber neuropathy. Muscle Nerve. 2002;26(2):173-88.

19. Lechlen JR, ChiesA-Estomba CM, De Siati DR, Horoi M, Le Bom S D, Rodriguez A et al. Olfactory and gustatory dysfunctions as a clinical presentation of mild-to-moderate forms of the coronavirus disease (COVID-19): a multicenter European study. Eur Arch Otorhinolaryngol. 2020;277(8):2251-61.

20. Netland J, Meyerholz DK, Moore S, Cassell M, Perlman S. Severe acute respiratory syndrome coronavirus infection causes neuronal death in the absence of encephalitis in mice transgenic for human ACE2. J Virol 2008;82(15):7264-75.

\section{CONFLICTS OF INTERESTS}

The authors declare no conflicts of interests.

\section{CORRESPONDING AUTHOR}

\section{Cristiano Gaujac}

Rua Antônio Barbosa de Araujo, 101

Bairro Farolândia

49031-090 Aracaju - SE, Brazil

Telephone: +55 79981391479

E-mail: cgaujac@gmail.com
Received 02/02/2021

Accepted 28/02/2021 